Article

\title{
Vapour Phase Hydrogenation of Phenol over Rhodium on SBA-15 and SBA-16
}

\author{
Liliana Giraldo ${ }^{1, \dagger}$, Marlon Bastidas-Barranco ${ }^{2, \dagger}$ and Juan Carlos Moreno-Piraján ${ }^{3, \dagger, *}$ \\ 1 Departamento de Química, Universidad Nacional de Colombia, Bogotá 110911, Colombia \\ 2 Departamento de Ingeniería Mecánica, Facultad de Ingeniería, Universidad de la Guajira, \\ Riohacha 440001, Colombia \\ 3 Grupo de Investigación en Sólidos Porosos y Calorimetría, Departamento de Química, \\ Universidad de los Andes, Bogotá 110911, Colombia
}

$\dagger$ These authors contributed equally to this work.

* Author to whom correspondence should be addressed; E-Mail: jumoreno@uniandes.edu.co; Tel.: +57-1-3394949.

External Editor: Geoffrey L. Price

Received: 22 September 2014; in revised form: 17 November 2014 / Accepted: 24 November 2014 / Published: 10 December 2014

\begin{abstract}
In the present work, mesoporous SBA-15 and SBA-16 were synthesised using classical methods, and their physicochemical properties were investigated by X-ray diffraction (XRD), FTIR, TEM and $\mathrm{N}_{2}$ adsorption-desorption. Rhodium (Rh, 1 wt \%) was loaded on the mesoporous SBA-15 and SBA-16 by an impregnation method. The Rh surface coverage, dispersion and crystallite size were determined by room temperature $\mathrm{H}_{2}$ chemisorption on reduced samples. The catalytic activity of Rh supported on mesoporous SBA-15 and SBA-16 was evaluated for the first time in the hydrogenation of phenol in vapour phase in a temperature range between 130 and $270{ }^{\circ} \mathrm{C}$ at atmospheric pressure. The reaction over $\mathrm{Rh} / \mathrm{SBA}-15$ at $180{ }^{\circ} \mathrm{C}$ produced cyclohexanone as the major product (about $60 \%$ ) along with lower amounts of cyclohexanol (about 35\%) and cyclohexane (about $15 \%$ ). The influences of temperature, $\mathrm{H}_{2} /$ phenol ratio, contact time and the nature of the solvent on the catalytic performance were systematically investigated. The $\mathrm{Rh} / \mathrm{SBA}-16$ system offered lower phenol conversion compared to Rh/SBA-15, but both have a very high selectivity for cyclohexanone (above 60\%).
\end{abstract}


Keywords: phenol hydrogenation; mesoporous materials; rhodium/SBA; zeolites

\section{Introduction}

The adequate cleaning of industrial wastewaters is a problem of major concern nowadays. New and more stringent regulations are being imposed, which suggest the need to develop and implement efficacious treatment technologies capable of dealing with the hazardous pollutants present in many industrial waste streams. Phenols and its derivatives are compounds that form part of the reactions for many processes in the pharmaceutical, petrochemical and polymer production industries whose wastewaters may contain phenolic compound concentrations ranging from 500 to $4000 \mathrm{mg} \cdot \mathrm{L}^{-1}[1,2]$. Several techniques are used for the removal of phenolic compounds from water as incineration or biological methods, which have some limitations [3]. Advanced oxidation processes such as wet air oxidation, Fenton, or photochemical processes have been studied extensively, showing some drawbacks or limitations such as the relatively high temperatures and/or pressures needed, large amounts of reagents and complex equipment, etc. [4-6]. Catalytic hydrogenation of phenol is an emerging and promising alternative attending to environmental criteria since a biodegradable and much less toxic product (i.e., cyclohexanol) can be obtained $[7,8]$. The hydrotreatment of phenol can follow two routes: hydrogenolysis or hydrogenation, depending on the reaction conditions. More severe conditions (temperatures and pressures higher than $200{ }^{\circ} \mathrm{C}$ and 10 bar, respectively) favour hydrogenolysis in which $\mathrm{C}-\mathrm{OH}$ bonds are broken, yielding benzene, cyclohexene and cyclohexane [9]. When hydrogenation is performed under moderate conditions, cyclohexenol is obtained in a first step. This intermediate readily disappears by two routes, reacting with hydrogen to produce cyclohexanol or evolving via isomerisation to cyclohexanone that can further react with hydrogen to also produce cyclohexanol $[10,11]$. The product distributions resulting from phenol hydrogenation are a function of the catalyst and the reaction conditions used [12-14].

One product of the phenol hydrogenation is cyclohexanone, which is used in the production of caprolactam for the synthesis of nylon-6 [15]. The former route requires high temperatures and pressures and generates undesirable by-products that lower the product yield and complicate the recovery/separation steps. The preparation of cyclohexanone by one-step hydrogenation of phenol is catalysed by $\mathrm{Pd}$ supported on $\mathrm{Al}_{2} \mathrm{O}_{3}$, and over $\mathrm{MgO}$-based catalysts [16,17]. The $\mathrm{Al}_{2} \mathrm{O}_{3}$-supported $\mathrm{Pd}$ catalysts, however, have a low resistance to deactivation by coke deposition. The use of $\mathrm{MgO}$ as a catalyst support on an industrial scale has drawbacks as well, mainly a low surface area and poor mechanical strength. Recently, $\mathrm{MgO}-\mathrm{Al}_{2} \mathrm{O}_{3}$ mixed oxides derived from hydrotalcite (HT)-like compounds (MgAl-CHT) have also been used as a support [18,19]. When $\mathrm{Pd}$ is supported on a porous material with a certain surface, phenol is adsorbed and receives $\mathrm{H}_{2}$ that binds to the aromatic ring following a spill-over mechanism [20,21]. The manner in which the adsorption of phenol occurs varies with the surface chemistry of the solid and this mode directs the product selectivity to cyclohexanone or cyclohexanol. For instance, phenol is adsorbed on acidic supports in a co-planar fashion with respect to the surface, while on basic supports it is adsorbed in a non-planar fashion. Hydrogenation of the former mode of adsorption leads to cyclohexanol preferentially. 
Mesoporous materials are inorganic or mixed organic-inorganic solids, which are synthesised by incorporating specific molecular species from a solution into their structure. Their layered or three-dimensional structural frameworks are porous in one or more directions, with correspondingly low densities. Their structural frameworks may be crystalline or amorphous, and the template or structure-directing agent (SDA) is co-crystallised in pores, channels, or interlayers. Additional solvent molecules (usually, but not necessarily water) are also often present in the structure.

Some results have been published on hydrogenation of phenol with different materials. It has been reported that $\mathrm{Pd} / \mathrm{Al}_{2} \mathrm{O}_{3}$ and $\mathrm{Pd} / \mathrm{SiO}_{2}$ catalysts containing $\mathrm{Pd}$ nanoparticles in the size range of $3-13 \mathrm{~nm}$ were prepared and investigated in a direct selective hydrogenation of phenol to cyclohexanone. Conversion of $99 \%$ was then obtained; a selectivity higher than $99 \%$ was achieved within $3 \mathrm{~h}$ at $333 \mathrm{~K}[22]$. The hydrogenation of phenol in aqueous phase for the study of a continuous trickle bed reactor was used with commercial and some home-made Pd/activated carbon (AC) catalysts for the treatment of phenolic wastewaters [23]. The catalyst of Rh nanoparticles supported on a carbon nanofibre, 5 wt $\% \mathrm{Rh} / \mathrm{CNF}$, with an average size of $2-3 \mathrm{~nm}$ was prepared by a method of incipient wetness impregnation. This catalyst presents a high activity in the ring hydrogenation of phenol in a medium of supercritical $\mathrm{CO}_{2}\left(\mathrm{scCO}_{2}\right)$ at a low temperature of $323 \mathrm{~K}$ [24]. Other interesting papers on this subject are those that use silica supported $\mathrm{Pd}$ and $\mathrm{PdAYb}$ catalysts [25] in vapour phase, $\mathrm{Pd} / \mathrm{Al}_{2} \mathrm{O}_{3}-\mathrm{CWE}$ in the hydrogenation of phenol in aqueous phase [26], and selective hydrogenation of phenol to cyclohexanone over palladium supported on calcined $\mathrm{Mg} / \mathrm{Al}$ hydrotalcite [27].

Some studies on hydrogenation of phenol have been published using rhodium nanoparticles supported on SBA-15 in the presence of supercritical $\mathrm{CO}_{2}\left(\mathrm{scCO}_{2}\right)$ where interesting results were obtained because of the ability of $\mathrm{scCO}_{2}$ to penetrate inside the meso-channels [28].

The SBA-15 has been used in various catalytic processes such as transesterification of canola oil over sulfated Ti/SBA-15 catalysts for making biodiesel [29], benzene oxidation with ozone [30], hydrolytic hydrogenation of cellulose [31], oxidative degradation of pentabromophenol in the presence of humic substances, and in hydroxylation of phenol by $\mathrm{H}_{2} \mathrm{O}_{2}$ [32].

In fact, a higher hydrogenation rate of propyne to propene has been observed over $\mathrm{Pd} / \mathrm{ZrO}_{2}$ catalyst compared to $\mathrm{Pd} / \mathrm{Al}_{2} \mathrm{O}_{3}$ or $\mathrm{Pd} / \mathrm{SiO}_{2}$ catalysts [18]. Recently, Ru-supported $\mathrm{ZrO}_{2}$ has been found to possess good catalyst activity in the selective hydrogenation of benzene to cyclohexene [19]. In order to obtain materials with a high surface area and ordered pore structures, many research efforts are currently underway on the synthesis of mesoporous type SBA-15 and SBA-16 zeolites using various synthesis pathways [16-18]. Although several approaches have been suggested to synthesise SBA zeolites, the retention of a regular pore structure after calcination has been observed. The structural properties of the SBA support also play an important role in the synthesis of catalysts. To obtain a stable mesoporous SBA-15 and SBA-16support, a good interaction between the inorganic species and metal should be assured. It is generally accepted that the use of a high surface area mesoporous support, rather than a commercial, low surface area support, for precious metals or transition metals has some beneficial effect on the catalytic performance. The mesoporous solids have a higher dispersion of reduced metal particles and, as a consequence, would show an improved catalytic performance [26-32].

The aim of the present study is to investigate the use of SBA-15 and SBA-16 as supports for Rh for the catalytic hydrogenation of phenol. The influences of temperature, $\mathrm{H}_{2} /$ phenol ratio, contact time and 
the nature of the solvent on the catalytic performance were analysed. Finally, experimental results are compared with the corresponding ones obtained using $\mathrm{Pd}$ supported on $\mathrm{Al}_{2} \mathrm{O}_{3}, \mathrm{MgO}$, and MgAl-CHT — supports possessing only acid-base properties.

\section{Results and Discussion}

\subsection{Characterisation of SBA-15 Support and Rh/SBA-15 Catalysts}

\subsubsection{Nitrogen Physisorption}

Figure 1 shows the nitrogen adsorption-desorption isotherms for the SBA-15 support and Rh-impregnated SBA-15 catalyst (Rh/SBA-15), while Figure 2 depicts the corresponding pore size distributions for these materials using the BJH theory [33-38].

Figure 1. Nitrogen adsorption/desorption of SBA-15 and Rh/SBA-15 catalyst (1 wt \%) and $\mathrm{N}_{2}$ sorption isotherms of the samples SBA-16 and $\mathrm{Rh} / \mathrm{SBA}-16$ (1 wt \% in Rh).
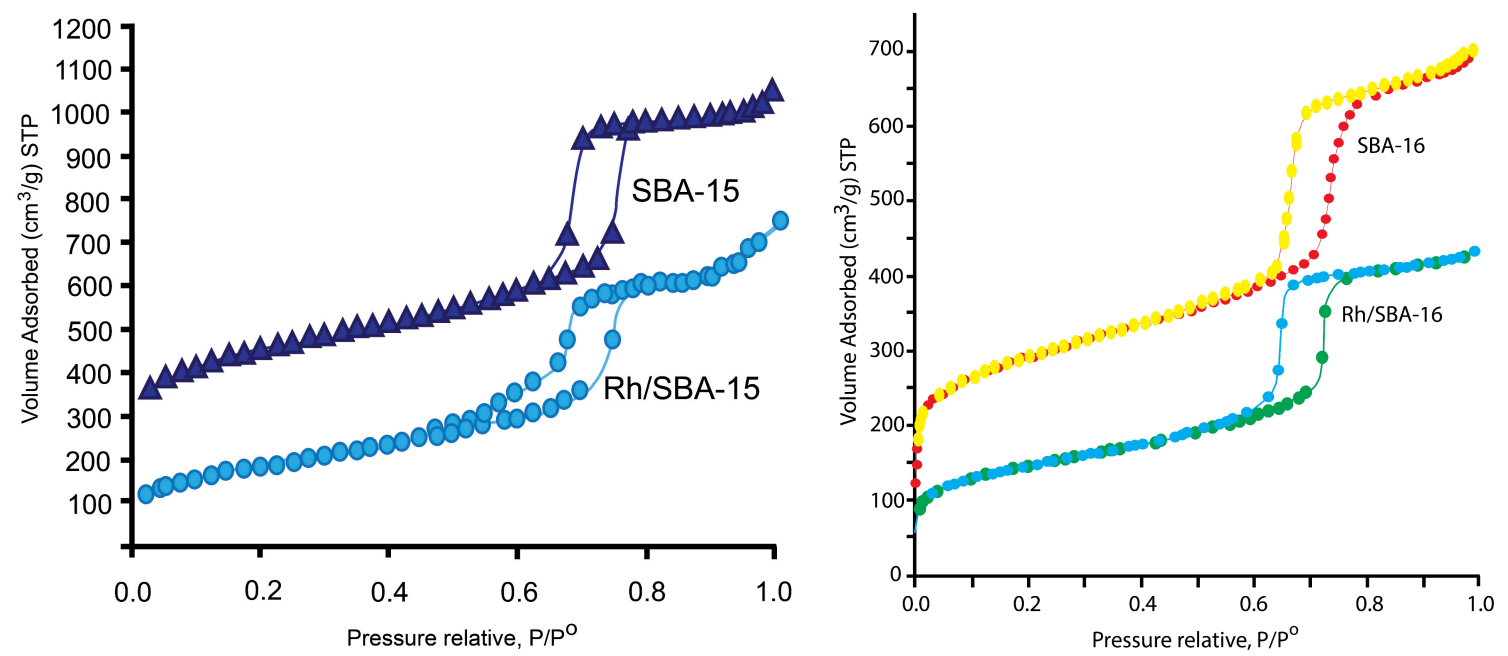

Figure 2. Pore size distribution of (a) SBA-15 compared with Rh/SBA-15 (1 wt \%) and (b) SBA-16 compared with Rh/SBA-16.

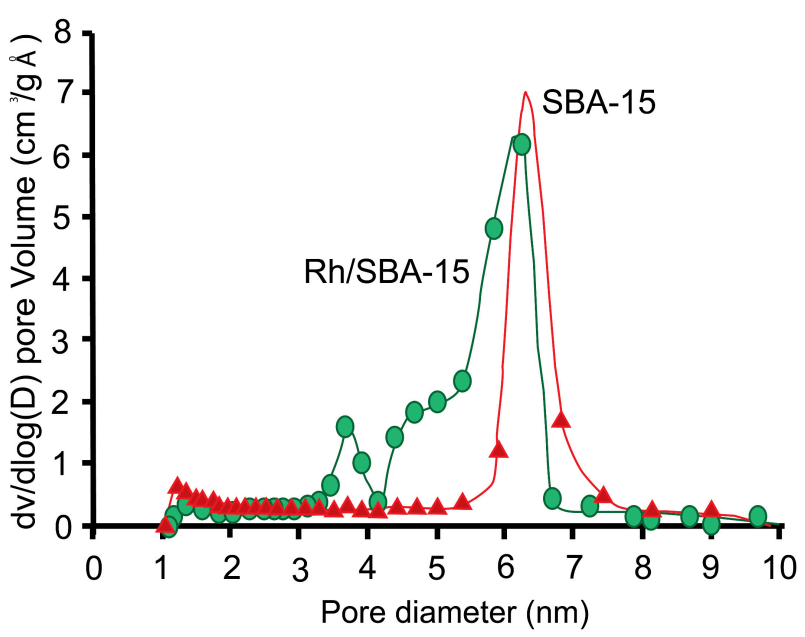

(a)

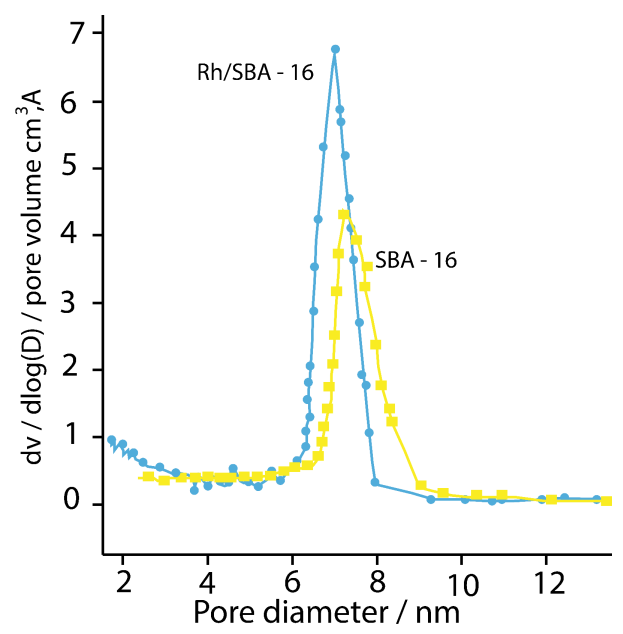

(b) 
The obtained isotherms are typical for well-defined mesoporous frameworks [35,36,38]. The shape of SBA-15 and Rh/SBA-15 (1 wt \% in Rh) isotherms (Figure 1) corresponds to type IV according to IUPAC classification, and displayed a broad H1 type hysteresis loop characteristic of large pore mesoporous solids [37-39]. The initial increase in adsorption capacity at low relative pressure is due to monolayer adsorption in the mesopores. The upward deviation in the range of $\mathrm{P} / \mathrm{P}^{0}=0.50-0.75$ is associated with the progressive filling of the mesopores. As the relative pressure increases, all the isotherms display a slope increase characteristic of capillary condensation inside uniform mesopores. The SBA-15 silica material exhibited a narrow pore size distribution comparable to the results reported in the literature for this type of material [40-42]. The capillary condensation step on the nitrogen adsorption isotherm of $\mathrm{Rh} / \mathrm{SBA}-15$ (1 wt \%) was found to be broad, indicating a wider range of pore sizes, as confirmed by the $\mathrm{BJH}$ pore size distribution (Figure 2). Figure 2 displays $\mathrm{N}_{2}$ pore size distributions of SBA-15 and Rh/SBA-15 (1 wt \% in Rh) samples. Indeed, the pore size distribution of Rh/SBA-15 (1 wt \%) shows a peak at $6.8 \mathrm{~nm}$. Furthermore, the Rh-containing SBA-15 retained the SBA-15 mesoporous structure, showing a relatively high specific surface area indicating that this catalyst retained the well-ordered 2D hexagonal array of the SBA-15 support. This suggests that the deposition and impregnation of Rh particles within the mesoporous silica did not seriously affect or block the mesoporous framework channels. Table 1 summarises the textural properties of the SBA-15 support as well as the $\mathrm{Rh} / \mathrm{SBA}-15$ catalyst. It is shown that the BET surface area of SBA-15 is $910 \mathrm{~m}^{2} \cdot \mathrm{g}^{-1}$ with a total pore volume of $1.39 \mathrm{~cm}^{3} \cdot \mathrm{g}^{-1}$ and $7.2 \mathrm{~nm}$ pore size Moreover, a moderate decrease in the BET surface area and pore volume of $\mathrm{Rh} / \mathrm{SBA}-15$ catalyst is observed.

Similarly, the SBA-16 and Rh/SBA-16 samples exhibited a type-IV isotherm pattern with an $\mathrm{H} 2$ hysteresis loop between the partial pressure $\mathrm{P} / \mathrm{P}^{0}=0.60-0.8$ (Figure 2a) for $\mathrm{Rh} / \mathrm{SBA}-16$ and $\mathrm{P} / \mathrm{P}^{0}=0.65-0.85$. It is shown that $\mathrm{Rh} / \mathrm{SBA}-16$ maintained the mesoporous structure of the parent SBA-16. The BET surface area changed from 655 to $575 \mathrm{~m}^{2} \cdot \mathrm{g}^{-1}$, the pore volume from 1.01 to $0.68 \mathrm{~cm}^{3} \cdot \mathrm{g}^{-1}$ and pore size from 7.3 to $7.6 \mathrm{~nm}$. The significant decreases in these physical parameters imply that rhodium atoms are introduced into the structure of SBA-16.

Table 1. Textural properties of catalysts with SBA-15 and SBA-16.

\begin{tabular}{cccc}
\hline Catalyst & $\mathbf{S}_{\text {BET }}\left(\mathbf{m}^{\mathbf{2}} \mathbf{g}^{-\mathbf{1}}\right)$ & $\mathbf{D}_{\text {BJH }}(\mathbf{n m})$ & $\mathbf{V}_{\text {BJH }}\left(\mathbf{c m}^{\mathbf{3}} \mathbf{g}^{-\mathbf{1}}\right)$ \\
\hline Rh/SBA-16 & 575 & 7.3 & 0.68 \\
SBA-16 & 655 & 7.6 & 1.01 \\
Rh/SBA-15 & 625 & 6.8 & 1.03 \\
SBA-15 & 910 & 7.2 & 1.39 \\
\hline
\end{tabular}

$\mathrm{S}_{\mathrm{BET}}$, specific surface area $\left(\mathrm{m}^{2} \cdot \mathrm{g}^{-1}\right) ; \mathrm{V}_{\mathrm{BJH}}$, pore volume $\left(\mathrm{cm}^{3} \cdot \mathrm{g}^{-1}\right) ; \mathrm{D}_{\mathrm{BJH}}$, pore diameter $(\mathrm{nm})$.

\subsubsection{Small and Wide Angle XRD}

The XRD patterns (not shown here) indicate that the rhodium-immobilised SBA-15 has an ordered structure. They also show three well-resolved peaks characteristics of this type of catalyst in which the metal structure is maintained once it is deposited in the solid. Rhodium is probably what forms a complex with the free electrons of the structure of SBA-15, obtaining a organised solid. The XRD pattern showed of the calcined sample exhibits three diffraction peaks corresponding to $\mathrm{d}\left(\begin{array}{lll}1 & 0 & 0\end{array}\right)$ of $15.3 \mathrm{~nm}, \mathrm{~d}\left(\begin{array}{lll}1 & 1 & 0\end{array}\right)$ of $8.3 \mathrm{~nm}$ and d (2 $\left.\begin{array}{lll}2 & 0\end{array}\right)$ of $5.4 \mathrm{~nm}$, which are a typical SBA-15 XRD reflection 
pattern. The incorporation of $\mathrm{RhCl}_{3}$ causes a marked intensity decrease of the three peaks. However, the basal (100) diffraction peaks are clearly observed. This indicates that the structure of SBA-15 remains intact through the supporting procedure. This is in good agreement with literature [40-43].

Similarly, the XRD analysis patterns of Rh/SBA-16 (not shown here) displayed a strong diffraction peak of the parent material SBA-16 at a low angle, suggesting that the highly ordered cubic mesoporous structure of SBA-16 was retained during the catalyst preparation. The low angle XRD patterns of SBA-16 were displayed in Figure 2. The SBA-16 exhibits two diffraction (110) and (200) peaks, characteristic of mesoporous materials [44].

\subsubsection{Transmission Electronic Microscope (TEM)}

In order to analyse the penetration into the SBA-16, we employed TEM to check the Rh particle sizes on the Rh/SBA-16 catalyst with a Rh loading of 1 wt \%. As shown in Figure 3a,b, the TEM images clearly display that the ordered pore structure of SBA-16 was retained after the catalyst preparation, and fine $\mathrm{Rh}$ particles were located inside the structure of SBA-16 with a narrow pore size distribution. Figure $3 \mathrm{~b}$ shows the particle distribution of the Rh on SBA-16; particle size was in a range of 1-5 nm and most of them have a size between 1-2 nm.

Figure 3. TEM micrographs of (a) SBA-16 silica material; (b) Rh/SBA-16 catalyst.

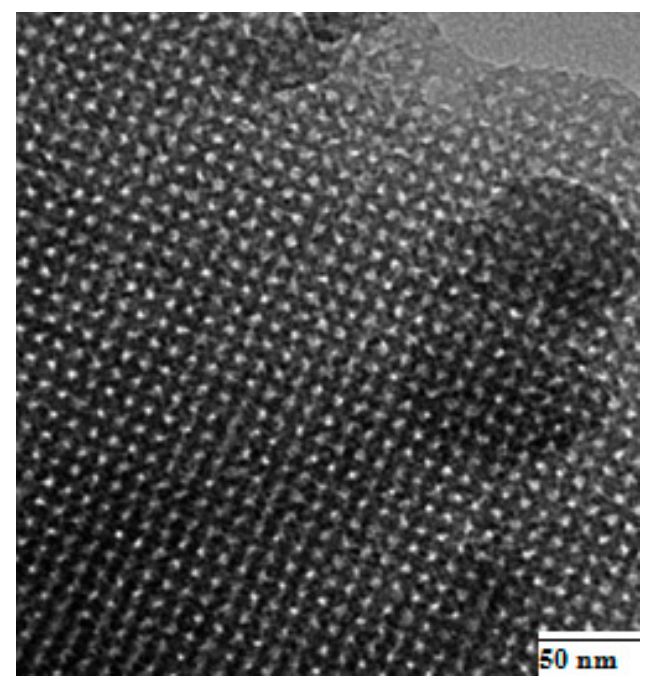

(a) SBA-16
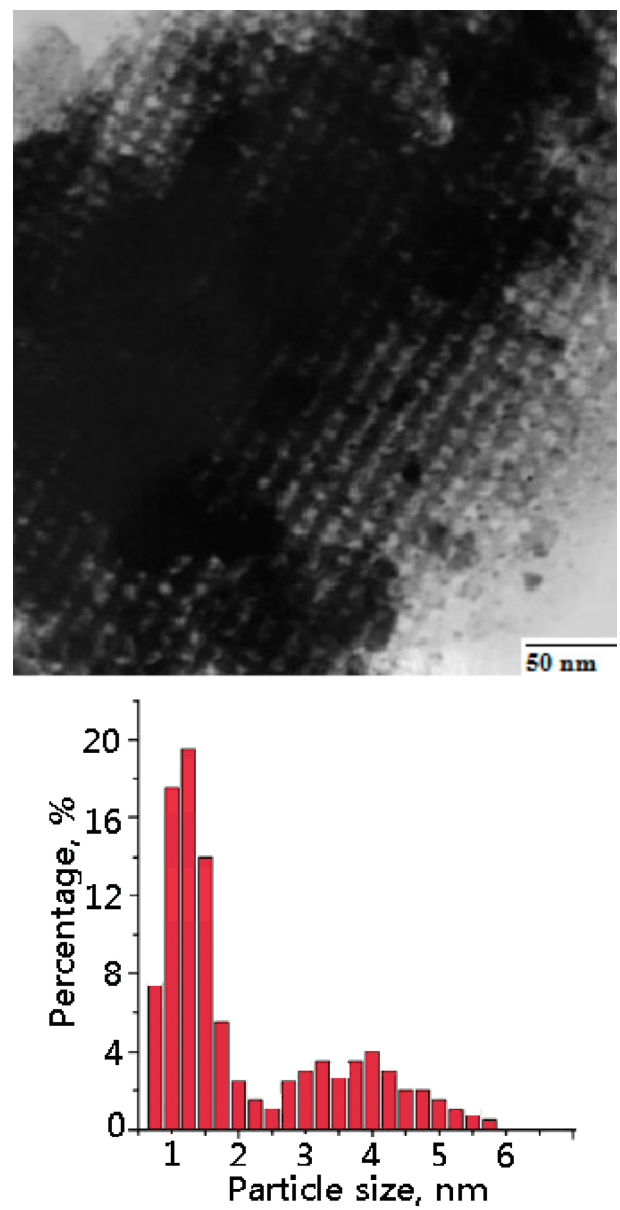

(b) $\mathrm{Rh} / \mathrm{SBA}-16$ 
The TEM images of SBA-15 and Rh/SBA15 catalysts are displayed in Figure 4. In the Rh/SBA-15 sample (Figure 4b), some small Rh-species attached to the siliceous walls seem to be present. The dispersion of $\mathrm{Rh}$ is related to the precursor molecules' characteristics. Indeed, these precursors can be easily diffuse into the SBA-15 tunnels around $7 \mathrm{~nm}$ in size and can be dispersed over the walls of the supporting materials. Figure $4 \mathrm{~b}$ shows the particle distribution of the Rh on SBA-15; particle size was in a range of 4-8 $\mathrm{nm}$ and most of them have a size between $4-5 \mathrm{~nm}$.

Figure 4. TEM micrographs of (a) SBA-15 silica material; (b) Rh/SBA-15 catalyst.
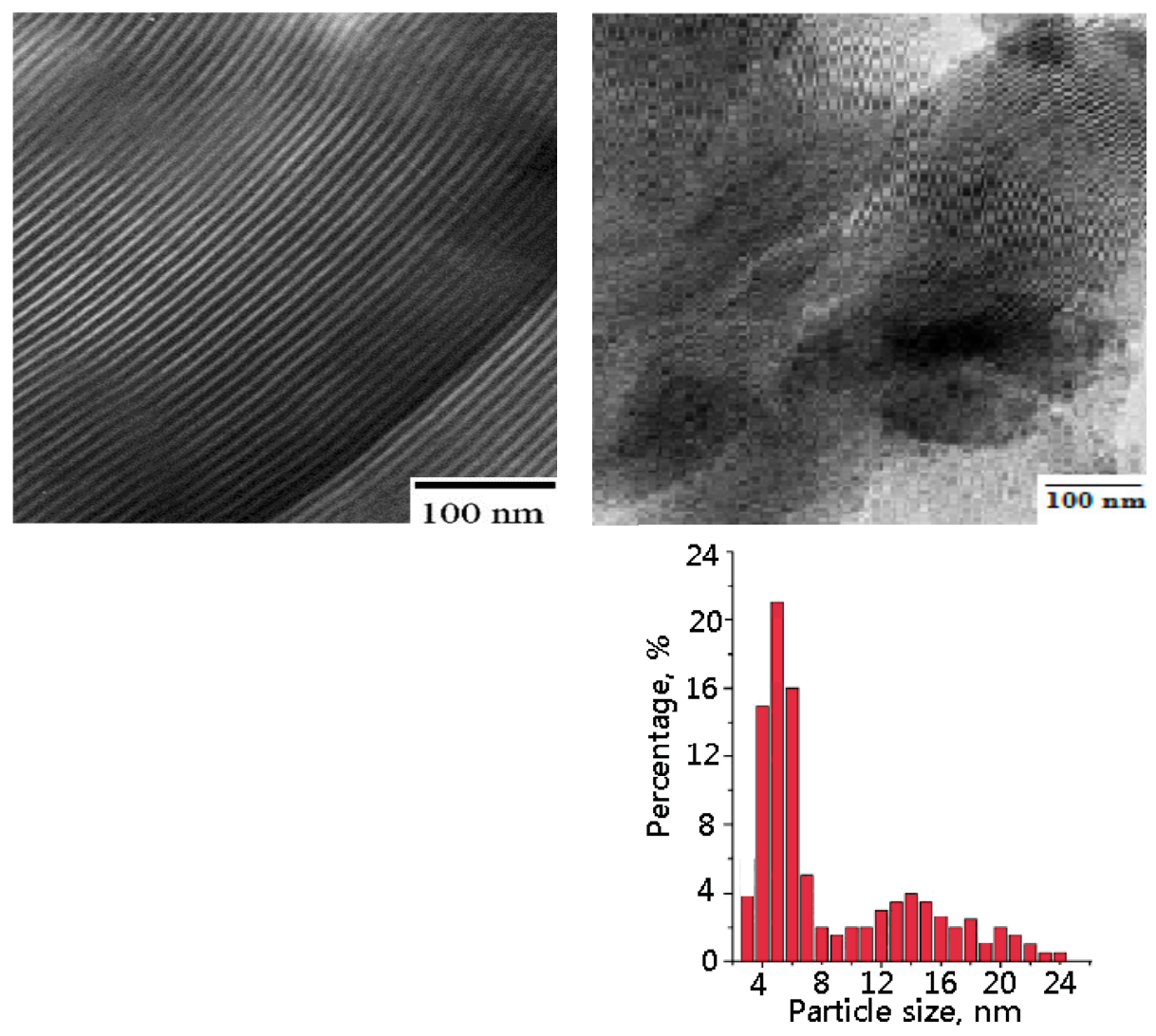

(a) TEM SBA-15

(b) TEM Rh/SBA-15

\subsubsection{Fourier Transform Infrared Spectroscopy (FTIR)}

The FT-IR spectra of SBA-16 and Rh/SBA-16 samples are shown in Figure 5. In comparison with the parent material SBA-16, two new peaks appeared at 2970 and $1560 \mathrm{~cm}^{-1}$ after modification with amino groups, which correspond to the stretching vibrations of the $\mathrm{C}-\mathrm{H}$ and the bending vibrations of $\mathrm{N}-\mathrm{H}$, respectively (the band at $1640 \mathrm{~cm}^{-1}$ was related to the water absorbed on solid surface). These results can confirm that amino groups were successfully grafted on SBA-16. Additionally, after modification, the intensity of the peak at $960 \mathrm{~cm}^{-1}$ corresponding to the bending vibrations of $\mathrm{Si}-\mathrm{OH}$ decreased significantly, proving that the amino groups were covalently linked with SBA-16 via a silylation. Simultaneously, a slight change in the remaining bands due to the presence of rhodium is observed $[45,46]$. 
Figure 5. FT-IR spectra od SBA-16 and Rh/SBA-16.

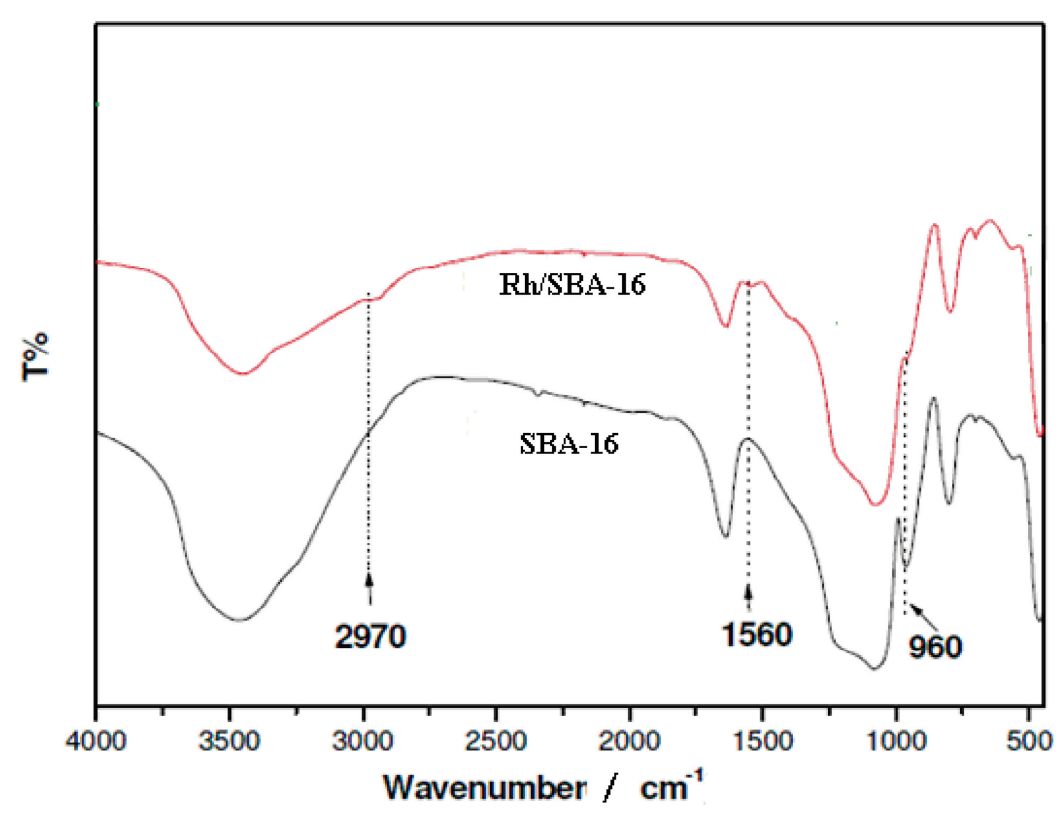

In the summary, both samples show typical bands at 1100 and $900 \mathrm{~cm}^{-1}$ in the skeletal region of framework vibrations, which are assigned to the asymmetric and symmetric stretching vibrations of $\mathrm{Si}-\mathrm{O}-\mathrm{Si}$ bridges, respectively [45]. In the hydroxyl region, the weak band at $1670 \mathrm{~cm}^{-1}$ and the broad band at $3500 \mathrm{~cm}^{-1}$ can be attributed to a combination of the stretching vibration of silanol groups with crosshydrogen bonding interactions and the $\mathrm{H}-\mathrm{O}-\mathrm{H}$ stretching mode of physisorbed water [45].

Figure 6. FT-IR spectra of SBA-15 and Rh/SBA-15.

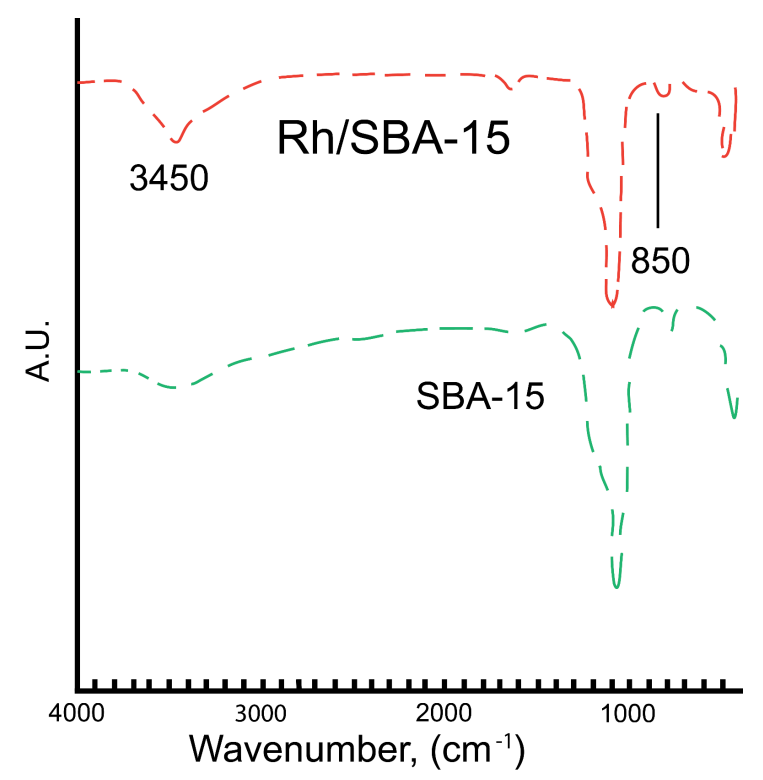

The Fourier transform infrared (FT-IR) spectra of pure SBA-15 and Rh-SBA-15 composite materials are shown in Figure 6. The bands around $3445 \mathrm{~cm}^{-1}$ can be assigned to the $\mathrm{O}-\mathrm{H}$ stretching vibrations mode of the silanols involved in hydrogen interactions with the adsorbed water molecules. The bands at around $1080 \mathrm{~cm}^{-1}$ and $850 \mathrm{~cm}^{-1}$ corresponded to characteristic anti-symmetric vibrations of non-bridging oxygen atoms $\left(\mathrm{Si}-\mathrm{O}^{\delta-}\right)$ of $\mathrm{Si}-\mathrm{O}-\mathrm{H}$ bonds and symmetric stretching vibrations $(\mathrm{Si}-\mathrm{O}-\mathrm{Si})_{\mathrm{sym}}$ 
of tetrahedral $\mathrm{SiO}_{4}$ structure units. Meanwhile, the band at around $460 \mathrm{~cm}^{-1}$ corresponds to the characteristic tetrahedral bending of Si-O bonds. No typical IR band located at around $960 \mathrm{~cm}^{-1}$ can be observed for the pure SBA-15. However, Rh-SBA-15 exhibits practically the same bands, shifting slightly in intensity [45-47]. Incorporation of the metal ion in the silica is observed around $960 \mathrm{~cm}^{-1}$ which corresponds to the vibration of Si-O affected by the presence of the ion $[45,46]$.

\subsection{Hydrogenation of Phenol over Rh/SBA}

The hydrogenation of phenol over $\mathrm{Rh} / \mathrm{SBA}-15$ and $\mathrm{Rh} / \mathrm{SBA}-16$ produced a mixture of cyclohexanone, cyclohexanol and cyclohexane. The phenol conversion and the product selectivity depend strongly on the type of catalyst used and on the reaction conditions used. Figure 7 illustrates the effect of the catalyst on phenol conversion. The phenol conversion reaches $95 \%$ for $\mathrm{Rh} / \mathrm{SBA}-15$ and $75 \%$ for $\mathrm{Rh} / \mathrm{SBA}-16$. This result can be closely related to the amount of chemisorbed $\mathrm{H}_{2}$ $\left(0.038 \mathrm{mmol} \cdot \mathrm{g}^{-1}\right.$ for $\mathrm{Rh} / \mathrm{SBA}-15$ and $\left.0.026 \mathrm{mmol} \cdot \mathrm{g}^{-1}\right)$ and, then, to the Rh metal surface coverage.

Figure 7. Conversion of phenol with $\mathrm{Rh} / \mathrm{SBA}-15$ and $\mathrm{Rh} / \mathrm{SBA}-16$.

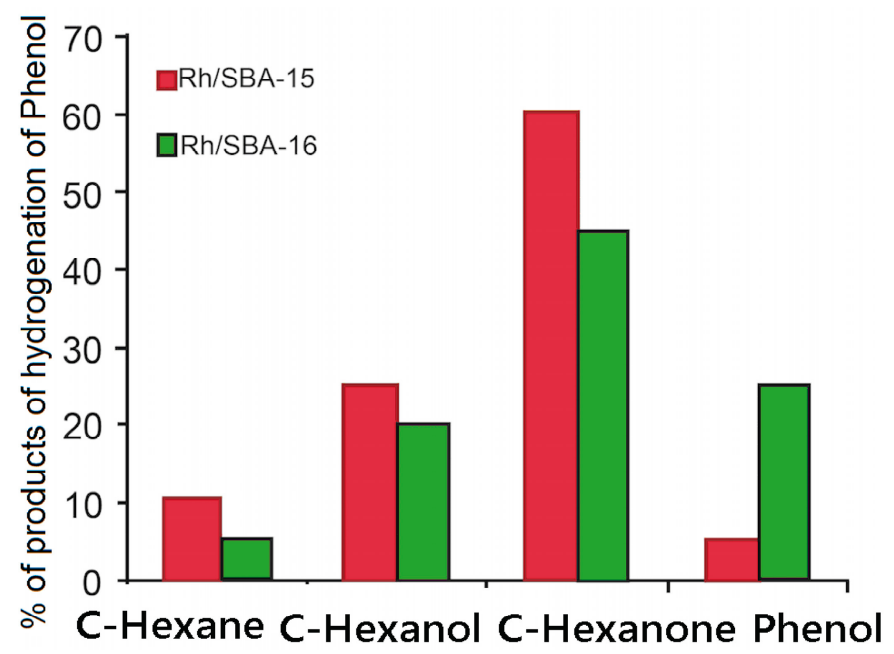

Reaction conditions: $=180{ }^{\circ} \mathrm{C}$. benzene/phenol $=2.0 ; \mathrm{H}_{2} /$ phenol $=6$; weight catalyst $=0.6 \mathrm{~g} ; \mathrm{WHSV}=$ $27 \mathrm{~mol} \cdot \mathrm{h}^{-1} \cdot \mathrm{kg}^{-1}$ (catalyst) ${ }^{-1}$.

Thus, the catalytic activity for phenol conversion increases with the type of SBA used as support for $\mathrm{Rh}$ and also with the quantity of Rh metal atoms exposed on the surface of the SBA. In summary, Figure 7 shows that the \% conversion for Rh/SBA-15 and Rh/SBA-16 catalysts have the following behaviour, respectively:

$$
\begin{aligned}
& \text { C-Hexanone }>\text { C-Hexanol }>\text { C-Hexane }>\text { Phenol } \\
& \text { C-Hexanone }>\text { Phenol }>\text { C-Hexanol }>\text { C-Hexane }
\end{aligned}
$$

The maximum conversion percentage corresponds to C-Hexanone in both catalysts, being higher for $\mathrm{Rh} / \mathrm{SBA}-15$. It is observed that the major product of the hydrogenation of phenol is cyclohexanone; a marked difference between the amount of cyclohexanone produced by the catalyst Rh/SBA-15 (60\%) and the Rh/SBA-16 (45\%) is observed. A similar behaviour is observed for the other subproducts detected in this investigation. Undoubtedly, both catalysts produce a hydrogenation of phenol that is highly selective for cyclohexanone. 
This difference in catalytic activity may also be associated with the dispersion of rhodium on SBA-15 and SBA-16; by the catalytic results obtained and the XDR spectra, the rhodium has a greater dispersion onto SBA-15; and also considering the specific area BET, pore volume and size diameter, the phenol reacts more in the structure of the catalyst Rh-SBA-15.

In Scheme 1a, a schematic representation for the catalytic processes between phenol and $\mathrm{Rh} / \mathrm{SBA}-15$ catalyst is shown. The input and output of reactive and products are shown. In Scheme 1b, the entrance of phenol and its various catalytic products is also represented for the catalyst $\mathrm{Rh} / \mathrm{SBA}-16$.

Scheme 1. Reaction between phenol and SBA-15 and SBA-16. (a) SBA-15; (b) SBA-16.

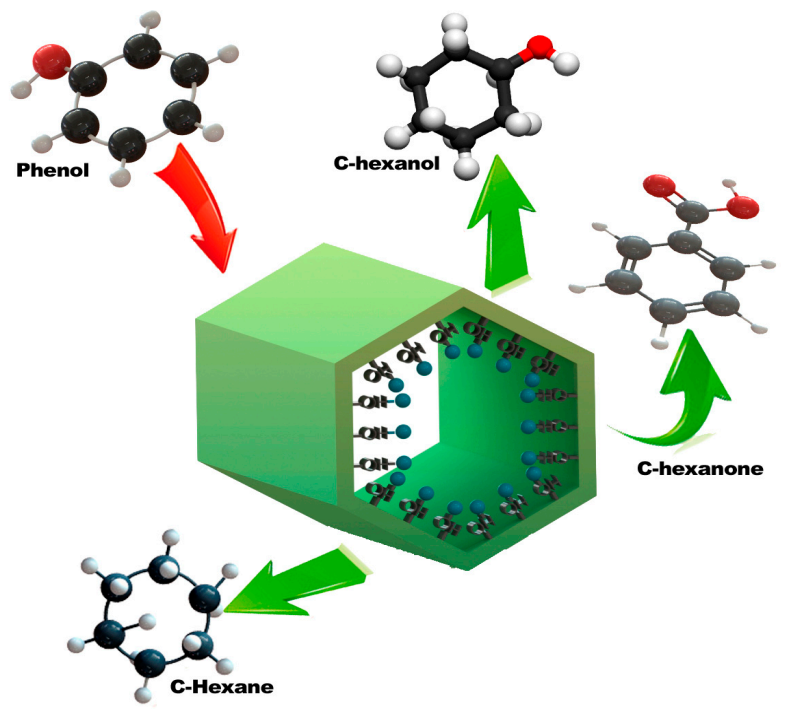

(a)

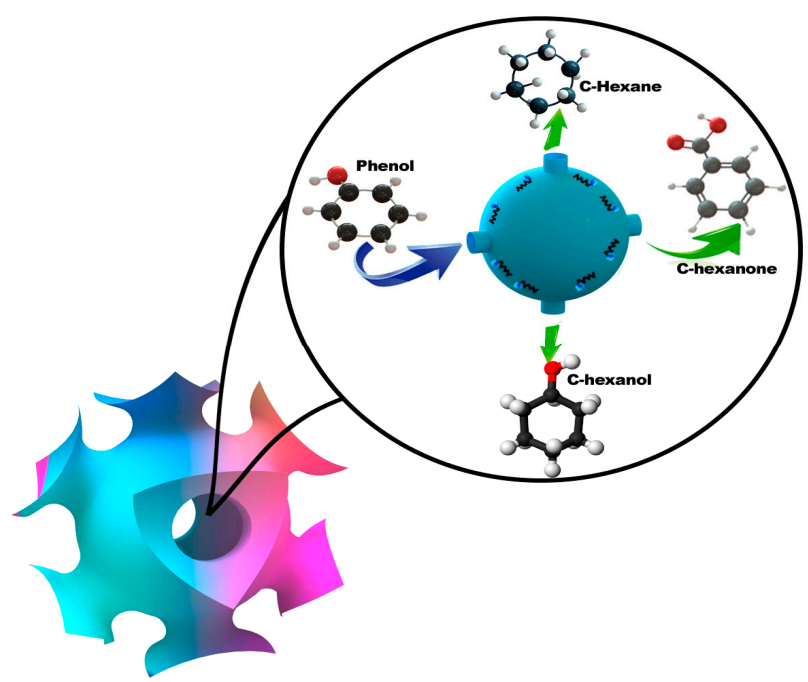

(b)

In Figure 8, the effect of temperature on catalytic performance over Rh/SBA-15 (with $1 \mathrm{wt} \%$ in $\mathrm{Rh})$ is shown.

Figure 8. Effect of temperature on the hydrogenation of phenol with $\mathrm{Rh} / \mathrm{SBA}-15$.

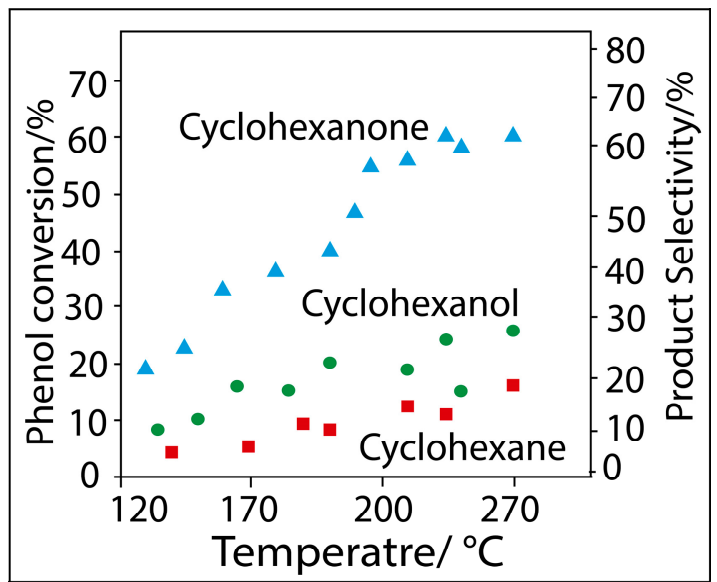

Reaction conditions: $=180{ }^{\circ} \mathrm{C}$. benzene/phenol $=2.0 ; \mathrm{H}_{2} /$ phenol $=6$; weight catalyst $=0.6 \mathrm{~g} ; \mathrm{WHSV}=$ $27 \mathrm{~mol} \cdot \mathrm{h}^{-1} \cdot \mathrm{kg}^{-1}$ (catalyst) $)^{-1}$.

A higher phenol conversion is obtained at $130^{\circ} \mathrm{C}$; the conversion decreased monotonously with the temperature. However it is noteworthy that the catalytic activity is higher with the catalyst $\mathrm{Rh} / \mathrm{SBA}-15$. 
It should be noted that Neri et al. [47] and Chen et al. [48] have also observed a maximum phenol conversion around $160{ }^{\circ} \mathrm{C}$ over $\mathrm{Pd}$ supported on alkali-doped $\mathrm{Al}_{2} \mathrm{O}_{3}$ and $\mathrm{MgAl}-\mathrm{CHT}$, respectively. With increasing temperature there is a decrease in the conversion of phenol caused by the lower presence of the reagent on the surface of the solid. Mahata et al. [10] on the other hand, observed a maximum phenol conversion around $230{ }^{\circ} \mathrm{C}$ over $\mathrm{Pd} / \mathrm{MgO}$ catalyst; here the decrease in phenol conversion with increasing temperature has been attributed to thermodynamic limitations. In order to ensure that the reaction took place in the vapour phase, in this study the operative conditions already published in the scientific literature were adopted, i.e., avoiding reaction temperatures below $120{ }^{\circ} \mathrm{C}$ since the boiling point of phenol is around $180^{\circ} \mathrm{C}$. The reaction temperature has a marked influence on the product selectivity as well. A nearly equimolar amount of cyclohexanone and cyclohexanol, together with traces of cyclohexane, are produced at $125{ }^{\circ} \mathrm{C}$. The selectivity of cyclohexanone increases with an increase in the reaction temperature, while the selectivity of cyclohexanol decreases for both Rh/SBA15 and Rh/SBA16. Similar results were also observed over Pt- and Pd-supported $\mathrm{Al}_{2} \mathrm{O}_{3} / \mathrm{MgO}$ catalysts [10,17] and also over $\mathrm{Ni} / \mathrm{SiO}_{2}$ catalysts [22]. However, in the case of $\mathrm{Pd} / \mathrm{MgAl}-\mathrm{CHT}$ catalysts the selectivity of cyclohexanone decreased with increasing temperature [49]. In the present study, the selectivity of cyclohexanone also increased to some extent up to $180{ }^{\circ} \mathrm{C}$ and then dropped off. The temperature $180^{\circ} \mathrm{C}$ was thus considered optimum and subsequent studies were performed at this temperature.

Figure 8 also shows that the reaction temperature has a profound influence on the product selectivity as well. A nearly equimolar amount of cyclohexanone and cyclohexanol, together with traces of cyclohexane, are produced at $130{ }^{\circ} \mathrm{C}$. The selectivity of cyclohexanone increases, while that of cyclohexanol decreases with increasing reaction temperature. In the present study, the selectivity of cyclohexane also increases to some extent up to $180^{\circ} \mathrm{C}$ and then levels off. The temperature of $180{ }^{\circ} \mathrm{C}$ was thus considered optimum and subsequent studies were performed at this temperature. The effect of $\mathrm{H}_{2} /$ phenol molar ratio on catalytic performance of $\mathrm{Rh} / \mathrm{SBA}-15$, resulting as the better catalyst, is shown in Figure 9.

Figure 9. Effect of $\mathrm{H}_{2} /$ phenol molar ratio on phenol conversion with $\mathrm{Rh} / \mathrm{SBA}-15$.

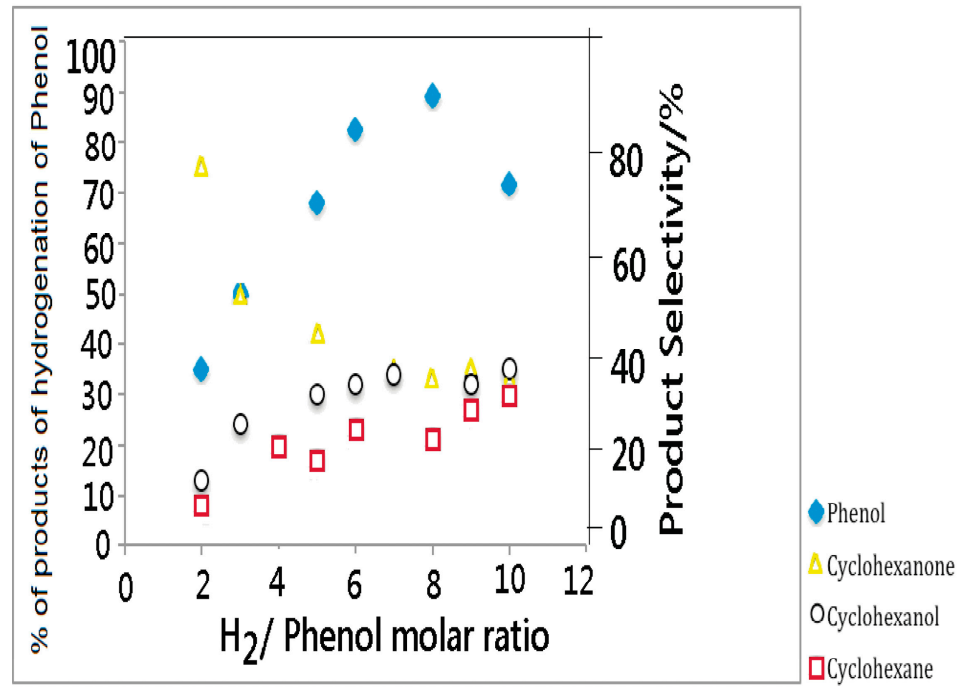

Reaction conditions: $=180{ }^{\circ} \mathrm{C}$. benzene/phenol $=2.0 ; \mathrm{H}_{2} /$ phenol $=6$; weight catalyst $=0.6 \mathrm{~g} ; \mathrm{WHSV}=$ $27 \mathrm{~mol} \cdot \mathrm{h}^{-1} \cdot \mathrm{kg}^{-1}(\text { catalyst })^{-1}$. 
The phenol conversion is sensitive to $\mathrm{H}_{2}$ partial pressure. The conversion increases dramatically from about $35 \%$ for $\mathrm{H}_{2} /$ phenol $=2$ to above $90 \%$ for the $\mathrm{H}_{2} /$ phenol $=9$. However, a further increase in $\mathrm{H}_{2}$ partial pressure has a detrimental effect on the phenol conversion. The increase in phenol conversion is accompanied by a complete hydrogenation of phenol to cyclohexane. At the lowest $\mathrm{H}_{2}$ /phenol ratio (i.e., equal to 2), the selectivity of cyclohexanone and cyclohexanol are about 75 and $35 \%$, respectively. The selectivity for cyclohexanone decreased monotonously, while the selectivity of cyclohexane decreased, when the $\mathrm{H}_{2} /$ phenol ratio was increased. The selectivity of cyclohexanol, on the other hand, is insensitive to the $\mathrm{H}_{2} /$ phenol ratio and it remains close to $30 \%$ in the entire range of $\mathrm{H}_{2} /$ phenol ratios examined. In order to understand the reaction pathway by which the phenol hydrogenation proceeds over $\mathrm{Rh} / \mathrm{SBA}-15$, the phenol conversion versus selectivity was analysed, as shown in Figure 10.

Figure 10. Phenol conversion in function of selectivity for hydrogenation over Rh/SBA15.

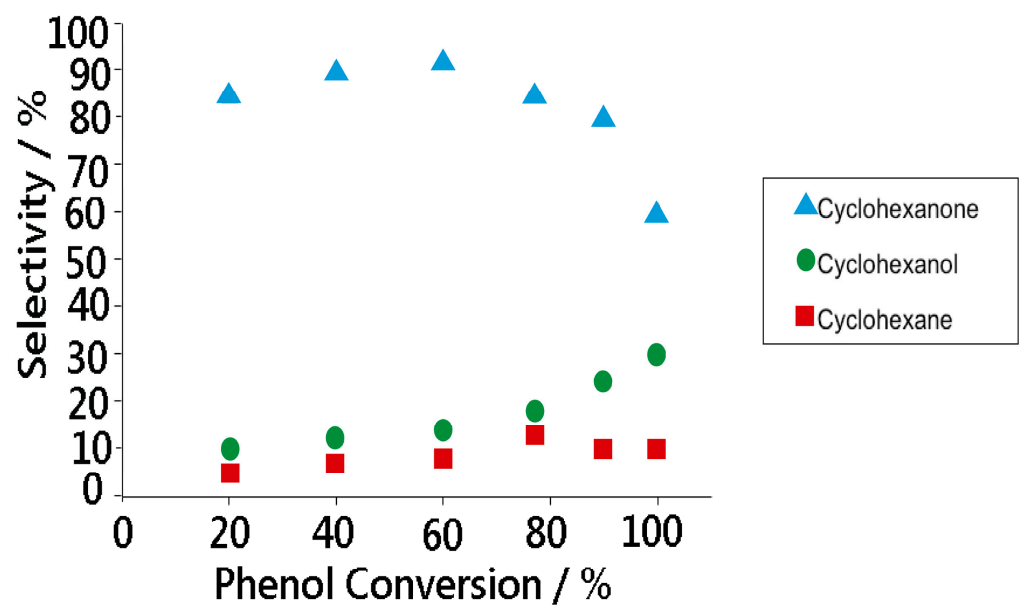

Reaction conditions: $=180{ }^{\circ} \mathrm{C}$. benzene/phenol $=2.0 ; \mathrm{H}_{2} /$ phenol $=6$; weight catalyst $=0.6 \mathrm{~g} ; \mathrm{WHSV}=$ $27 \mathrm{~mol} \cdot \mathrm{h}^{-1} \cdot \mathrm{kg}^{-1}$ (catalyst) ${ }^{-1}$.

It can be seen that cyclohexanone is the predominant product with a selectivity of more than $90 \%$ at low phenol conversions. As the conversion increases to about $65 \%$, the selectivity of cyclohexanone declines at the expense of the selectivity for cyclohexanol. Above this conversion level, in addition to cyclohexanol, cyclohexane and traces of cyclohexene are also produced and their selectivity increases with the phenol conversion. This is consistent with results previously reported in the scientific literature [49]. The results show that the cyclohexanone is the main product of the phenol hydrogenation, and by a subsequent hydrogenation of this cyclohexanol is obtained. The cyclic hydrocarbons, cyclohexane and cyclohexene can be produced by dehydration and hydrodeoxygenation of the above.

Figure 11 shows the phenol conversion at $\mathrm{T}=180{ }^{\circ} \mathrm{C}$ as a function of time-on-stream over $\mathrm{Rh} / \mathrm{SBA}-15$ and $\mathrm{Rh} / \mathrm{SBA}-16$ catalysts. In both cases, there is only a minor decrease in the phenol conversion (within 10\%) over the period of study $(8 \mathrm{~h}$ ). This minor deactivation does not alter the selectivity of cyclohexanone, which remains unchanged. If the selectivity of cyclohexanone can be improved to a satisfactory level by altering the composition of the support, this will probably be a good alternative catalyst for industrial production of cyclohexanone via phenol hydrogenation. 
Figure 11. Effect of contact time on catalytic performance in the hydrogenation of phenol over $\mathrm{Rh} / \mathrm{SBA}-15$ and $\mathrm{Rh} / \mathrm{SBA}-16$, Temperature $=180{ }^{\circ} \mathrm{C}$; benzene/phenol $=2.0$; $\mathrm{H}_{2} /$ phenol $=6 ; \mathrm{WHSV}=27 \mathrm{~mol} \cdot \mathrm{h}^{-1} \mathrm{~kg} \cdot$ catalyst $^{-1}$.

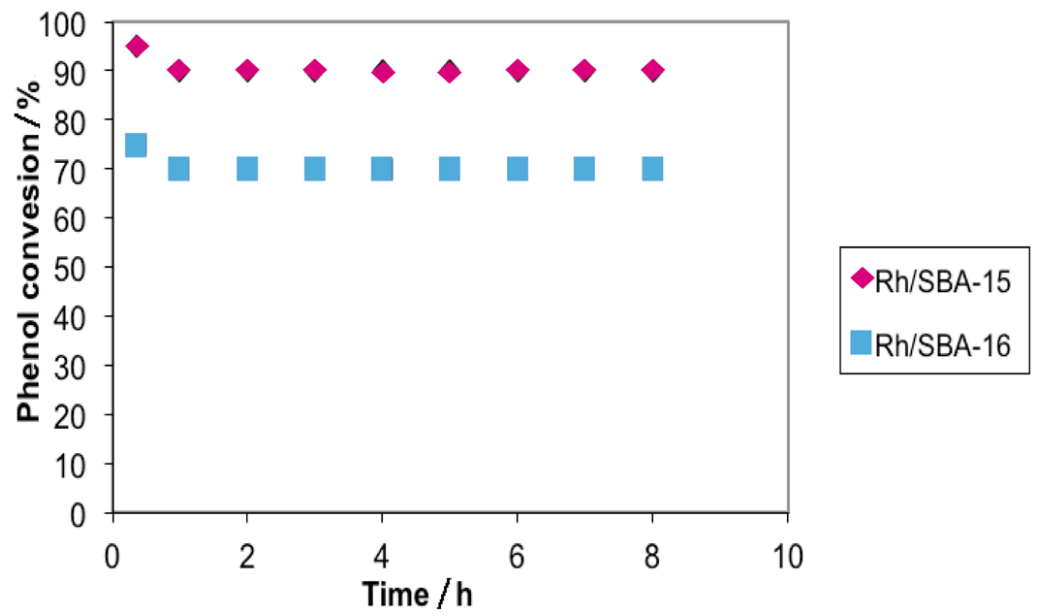

The effect of the nature of solvent for phenol on catalytic performance has also been investigated over Rh/SBA-15 and Rh/SBA-16 (not reported here). The use of cyclohexane or ethanol as a solvent to phenol in the hydrogenation reaction is already known in the literature [2-11]. As we mentioned in the Experimental Section (Section 3.3), the motivation for this study is to select a suitable solvent for phenol hydrogenation because the use of cyclohexane produced a considerable amount of benzene as a byproduct. Four different solvents, namely benzene, toluene, cyclohexane and ethanol, were tested under similar experimental conditions. On comparing the data collected over benzene, toluene and cyclohexane, one can conclude that a relatively higher conversion can be achieved using cyclohexane as a solvent. However, the cyclohexanone selectivity is the same in all three solvents, and its selectivity is not influenced by the nature of the solvent. An appreciable amount of cyclohexane is obtained only in the case of benzene (note that a part of cyclohexane might be formed from benzene), while only traces of cyclohexene are formed when using toluene as a solvent. On the other hand, a three-fold drop in phenol conversion is observed using ethanol as a solvent with the present catalyst system (Rh/SBA-15). The drop in phenol conversion could be due to a competitive adsorption of phenol and/or $\mathrm{H}_{2}$ and ethanol molecules on the same active site. Phenol can also undergo alkylation reactions to produce the corresponding alkyl phenols over the catalyst, if alcohols are used as a solvent [30-33]. Hence, alcohols (methanol and ethanol) are not suitable solvents for phenol in the hydrogenation reaction over the $\mathrm{Rh} / \mathrm{SBA}$ system.

\section{Experimental Section}

\subsection{Sample Preparation}

For the synthesis of mesoporous materials, a dedicated reactor was designed in our laboratory [39]. The reactor was constructed with Teflon and was provided with a controllable agitation system and pressure gauge. A safety valve was also installed, which enables the system to release excess pressure automatically, balancing the internal and external pressure [3-7]. 


\subsubsection{Synthesis of SBA-15}

For the synthesis of SBA-15 [4-8], Pluronic P123 triblock copolymer (8 g, EO $\left.{ }_{20} \mathrm{PO}_{70} \mathrm{EO}_{20}\right)$ was dissolved in $2 \mathrm{M} \mathrm{HCl}(300 \mathrm{~mL})$. Subsequently, tetraethyl orthosilicate (TEOS, $17 \mathrm{~g}$ ) was added under vigorous stirring at $318 \mathrm{~K}$. The molar ratio of the synthesis solution, TEOS:HCl: $\mathrm{H}_{2} \mathrm{O}: \mathrm{P} 123$, was 1:5.87:194:0.017. After $7.5 \mathrm{~h}$, stirring was stopped and the solution was aged for $15 \mathrm{~h}$ at $353 \mathrm{~K}$. Then, the resulting white powder was filtered, washed, and dried. Finally, the powder was calcined by heating from ambient temperature to $823 \mathrm{~K}$ for $6 \mathrm{~h}$, using a heating rate of $1 \mathrm{~K} \cdot \mathrm{min}^{-1}[48,49]$.

\subsubsection{Synthesis of SBA-16}

SBA-16 was prepared as described in [5]: triblock copolymer Pluronic F127 was added to an aqueous solution of $\mathrm{HCl}$, and stirred at a certain temperature overnight. Then, TEOS was added to this solution under vigorous stirring. After $10 \mathrm{~min}$ of stirring, the mixture was kept under static conditions at the aforementioned temperature for 3-72 $\mathrm{h}$. The resulting solid products were collected by filtration, washed with ethanol, dried, and calcined at $550{ }^{\circ} \mathrm{C}$ in air for $5 \mathrm{~h}$. Preparation of SBA-16 crystals relies on precise control of the reaction temperature and the ratio of reactants. Typical synthetic conditions for TEOS:F127:HCl: $\mathrm{H}_{2} \mathrm{O}$ were 1.00:0.0041:5.00:180 at $301 \mathrm{~K}$, to obtain 1.00:0.0053:4.10:150 at $305 \mathrm{~K}$, resulting in a rhomb-dodecahedron shape [49].

\subsubsection{Catalyst Synthesis}

Catalysts were prepared by impregnating SBA-15 and SBA-16 with an aqueous solution of $\mathrm{RhCl}_{3} \cdot 3 \mathrm{H}_{2} \mathrm{O}$ via incipient wetness technique. The impregnated powders were dried at $60{ }^{\circ} \mathrm{C}$ overnight. Calcination was carried out at $490{ }^{\circ} \mathrm{C}$ for $12 \mathrm{~h}$ at a heating rate of $10^{\circ} \mathrm{C} \cdot \mathrm{min}^{-1}$. The rhodium content was kept constant at $1 \mathrm{wt} \%$.

\subsection{Sample Characterisation}

The crystalline phases of the synthesised mesoporous materials were identified by X-ray diffractometry (XRD). Spectra were scanned from $2 \theta=1.0^{\circ}$ to $20^{\circ}$, at a rate of $1^{\circ} \mathrm{min}^{-1}$. Fourier transform infrared spectra (FT-IR) were collected on the samples from 400 to $4000 \mathrm{~cm}^{-1}$; the determination of inter-species bonding was carried out from the identification of functional groups in the infrared absorption spectra. Adsorption-desorption nitrogen isotherms were measured at the temperature of liquid nitrogen, using an Autosorb 3B (Quantachrome, Boyton Beach, MI, USA). The surface area was determined by applying the Brunauer-Emmett-Teller (BET) equation and specific pore volume was calculated according to the Barrett-Joyner-Halenda (BJH) theory [36-38]. Transmission electron microscopy (TEM) measurements were made on a JEM-3010 electron microscope (JEOL, Tokyo, Japan) with an acceleration voltage of $300 \mathrm{kV}$.

\subsection{Hydrogenation of Phenol}

The vapour phase hydrogenation of phenol was tested in a fixed-bed tubular glass reactor $(10 \mathrm{~mm}$ i.d. $\times 250 \mathrm{~mm})$ at atmospheric using $0.6 \mathrm{~g}$ of the catalyst in the temperature range $130-270{ }^{\circ} \mathrm{C}$, 
as reported in literature [49]. Before their catalytic behaviours were evaluated, the catalysts (around $0.15 \mathrm{~g}$ ) were reduced in situ at $598 \mathrm{~K}$ with a heating rate of $1{ }^{\circ} \mathrm{C} \cdot \mathrm{min}^{-1}$ under flowing hydrogen $\left(50 \mathrm{~cm}^{3} \cdot \mathrm{min}^{-1}\right)$ for $10 \mathrm{~h}$, then cooled under hydrogen to the reaction temperature. Preliminary experiments reported in the literature, using cyclohexane as a solvent indicated the formation of a significant amount (15-20 mol \%) of benzene [49]. Consequently, a series of solvents such as benzene, toluene, $n$-hexane and ethanol were examined. A considerable amount of benzene formation was also observed using toluene or $n$-hexane as solvents. Hence, in order to avoid the formation of benzene in the phenol hydrogenation, in the present study benzene itself was used as solvent. The hydrogenation of benzene to cyclohexane and other compounds using several catalyst systems is well known in the literature [47-49]. A blank experiment without phenol under the same experimental conditions produced an amount of cyclohexane (10-15 mol \%). However, the use of benzene as solvent for phenol hydrogenation is preferred because under the adopted experimental conditions, the hydrogenation of phenol is predominant if compared to the hydrogenation of benzene, as reported in the literature [43-49]. A premixed phenol and benzene with a benzene/phenol molar ratio $=2$ was fed into the pre-heater by means of a micro-feeder (liquid flow rate $=3.0 \mathrm{~cm}^{3} \cdot \mathrm{h}^{-1}$ ). $\mathrm{H}_{2}$ was used as carrier gas as well as reactant; its flow rate was adjusted using a mass flow controller in such a way that the $\mathrm{H}_{2} /$ phenol $=6$. Chromatographic analyses were performed with a HP PAS/5 $(25 \mathrm{~m} \times 0.32 \mathrm{~mm} \times 0.52 \mu \mathrm{m})$ capillary column (Hewlett Packard, Palo Alto, CA, USA), on a Shimadzu GC-17 (Kyoto, Japan) gas chromatographer with flame ionisation detector. Data between one and two hours were registered, then a comparative analysis and an interpretation of the results was completed.

The phenol conversion (\%) (\% phenol) is given by:

$$
\text { Phenol conversion }(\%)=[\text { Phenol }]_{\text {in }}-[\text { Phenol }]_{\text {out }}[\text { Phenol }]_{\text {out }} \times 100
$$

while reaction selectivity (as a percentage) in terms of the others compounds (i.e., cyclohexanone) formation can be represented by:

Selectivity $(\%)$ of Cyclohexanone $=[\text { Cyclohexanone }]_{\text {out }} /[\text { Phenol }]_{\text {in }}-[\text { Phenol }]_{\text {out }} \times 100$

\section{Conclusions}

Our study of hydrogenation of phenol over Rh supported on mesoporous SBA-15 and SBA-16 in showed that there an is appreciable catalytic performance in terms of phenol conversion, and cyclohexanone selectivity can be obtained over catalysts with $1 \mathrm{wt} \% \mathrm{Rh}$ loading. Additionally, under identical experimental conditions, the catalytic activity over mesoporous SBA-15 as support is better than over SBA-16 as support. The results of this study show that the Rh/SBA-15 exhibits stable activity during on-stream operation, but produces a mixture of cyclohexanone (about 60\%), cyclohexanol (about 35\%) and cyclohexane (about 15\%), with a phenol conversion of about $80 \%$ at $180{ }^{\circ} \mathrm{C}$. Finally, Rh/SBA-16 produces principally cyclohexanone for both synthesized catalysts in this work. The difference determined selectivity in this work is probably related with the structure of synthesized catalysts and mechanism of adsorption of the phenol. 


\section{Acknowledgments}

The authors wish to thank the Master Agreement established between the Universidad de los Andes and the Universidad Nacional de Colombia and the Memorandum of Understanding entered into by the Departments of Chemistry of both Universities. Special thanks go to the Faculty of Science and the Vice-Rectory of Research at the University of the Andes (Bogotá, Colombia) for funding this research.

\section{Author Contributions}

Giraldo (G), Bastidas-Barranco (BB) and Moreno-Piraján (MP) designed research; G, BB and MP performed research and analyzed the data; MP wrote the paper. All authors read and approved the final manuscript.

\section{Conflicts of Interest}

The authors declare no conflict of interest.

\section{References}

1. Dojido, J.R.; Best, G.A. Chemistry of Water and Water Pollution; Prentice Hall: New York, NY, USA, 1993; Chapter 4, Section 19.

2. Park, C.; Keane, M.A. Catalyst support effects: Gas-phase hydrogenation of phenol over palladium. J. Colloid Interface Sci. 2003, 266, 183-194.

3. Matatov-Meytal, Y.I.; Sheintuch, M. Catalytic abatement of water pollutants. Ind. Eng. Chem. Res. 1998, 37, 309-326.

4. Santos, A.; Yustos P.; Quintanilla, A.; García-Ochoa F.; Casas, J.A.; Rodríguez, J.J. Route of the catalytic oxidation of phenol in aqueous phase. Appl. Catal. B: Environ. 2002, 39, 97-113.

5. Pera-Titus, M.; Garcia-Molina, V.; Banos, M.A.; Gimenez, J.; Esplugas, S. Degradation of chlorophenols by means of advanced oxidation processes: A general review. Appl. Catal. B: Environ. 2004, 47, 219-256.

6. Zazo, J.A.; Casas, J.A.; Mohedano, A.F.; Gilarranz, M.A.; Rodríguez, J.J. Chemical pathway and kinetics of phenol oxidation by Fenton's reagent. Environ. Sci. Technol. 2005, 39, 9295-9302.

7. Srinivas, S.T.; Jhansi Lakshmi, L.; Kanta Rao, P. Selectivity dependence on the alloying element of carbon supported Pt-alloy catalysts in the hydrogenation of phenol. Appl. Catal. A 1994, 110, 167-172.

8. Shin, E.-J.; Keane, M.A. Gas-phase hydrogenation/hydrogenolysis of phenol over supported nickel catalysts. Ind. Eng. Chem. Res. 2000, 39, 883-892.

9. Talukdar, A.K.; Bhattacharyya, K.G. Hydrogenation of phenol over supported platinum and palladium catalysts. Appl. Catal. A 1993, 96, 229-239.

10. Mahata, N.; Vishwanathan, V. Influence of palladium precursors on structural properties and phenol hydrogenation characteristics of supported palladium catalysts. J. Catal. 2000, 196, 262-270.

11. Calvo, L.; Mohedano, A.F.; Casas, J.A.; Gilarranz, M.A.; Rodríguez, J.J. Treatment of chlorophenols-bearing wastewaters through hydrodechlorination using $\mathrm{Pd} /$ activated carbon catalysts. Carbon 2004, 42, 1377-1381. 
12. Schuth, C.; Reinhard, M. Hydrodechlorination and Hydrogenation of Aromatic Compounds over Palladium on Alumina in Hydrogen-Saturated Water. Appl. Catal. B-Environ. 1998, 18, 215-221.

13. Calvo, L.; Mohedano, A.F.; Casas, J.A.; Gilarranz, M.A.; Rodríguez, J.J. Effects of support surface composition on the activity and selectivity of $\mathrm{Pd} / \mathrm{C}$ catalysts in aqueous-phase hydrodechlorination reactions. Ind. Eng. Chem. Res. 2005, 44, 6661-6667.

14. Díaz, E.; Mohedano, A.F.; Calvo, L.; Gilarranz, M.A.; Casas, J.A.; Rodríguez, J.J. Hydrogenation of phenol in aqueous phase with palladium on activated carbon catalysts. Chem. Eng. J. 2007, $131,65-71$.

15. Dodgson, I.; Griffin, K.; Barberis, G.; Piganttaro, F.; Tauszik, G. A low cost phenol to cyclohexanone process. Chem. Ind. 1989, 830-841.

16. Neri, G.; Visco, A.M.; Donato, A.; Milone, C.; Malentacchi, M.; Guibitosa, G. Hydrogenation of phenol to cyclohexanone over palladium and alkali-doped palladium catalysts. Appl. Catal. A 1994, 110, 49-55.

17. Mahata, N.; Raghavan, K.V.; Vishwanathan, V.; Park, C.; Keane, M.A. Phenol hydrogenation over palladium supported on magnesia: Relationship between catalyst structure and performance. Phys. Chem. Chem. Phys. 2001, 3, 2712-2722.

18. Cosimo, J.I.D.; Díez, V.K.; Xu, M.; Iglesia, E.; Apesteguía, C.R. Structure and Surface and Catalytic Properties of Mg-Al Basic Oxides. J. Catal. 1998, 178, 499-510.

19. Narayanan, S.; Krishna, K. Hydrotalcite-supported palladium catalysts: Part I: Preparation, characterization of hydrotalcites and palladium on uncalcined hydrotalcites for $\mathrm{CO}$ chemisorption and phenol hydrogenation. Catal. Today 1999, 49, 57-64.

20. Hu, S.; Xue, M.; Chen, H.; Shen, J. The effect of surface acidic and basic properties on the hydrogenation of aromatic rings over the supported nickel catalysts. Chem. Eng. J. 2010, 162, 371-379.

21. Graham, G.W.; Jen, H.-W.; McCabe, R.W.; Straccia, A.M.; Haack, L.P. Characterization of model automotive exhaust catalysts: Pd on Zr-rich ceria-zirconia supports. Catal. Lett. 2000, 67, 99-105.

22. Cheng, L.; Dai, Q.; Li, H.; Wang, X. Highly selective hydrogenation of phenol and derivatives over $\mathrm{Pd}$ catalysts supported on $\mathrm{SiO}_{2}$ and $\gamma-\mathrm{Al}_{2} \mathrm{O}_{3}$ in aqueous media. Catal. Commun. 2014, 57, 23-28.

23. González-Velasco, J.R.; González-Marcos, M.P.; Arnaiz, S.; Gutiérrez-Ortiz, J.I.; Gutiérrez-Ortiz, M.A. Activity and selectivity of palladium catalysts during the liquid-phase hydrogenation of phenol. Influence of temperature and pressure, Ind. Eng. Chem. Res. 1995, 34, 1031-1036.

24. Wang, H.; Zhao, F.; Fujita, S.I.; Arai, M. Hydrogenation of phenol in $\mathrm{scCO}_{2}$ over carbon nanofiber supported Rh catalyst. Catal. Commun. 2008, 9, 362-368.

25. Shore, S.G.; Ding, E.; Park, C.; Keane, M.A. Vapor phase hydrogenation of phenol over silica supported Pd and PdAYb catalysts. Catal. Commun. 2002, 3, 77-84.

26. Pérez, Y.; Fajardo, M.; Corma, A. Highly selective palladium supported catalyst for hydrogenation of phenol in aqueous phase. Catal. Commun. 2011, 12, 1071-1074.

27. Chen, Y.Z.; Liaw, C.W.; Lee, L.I. Selective hydrogenation of phenol to cyclohexanone over palladium supported on calcined Mg/Al hydrotalcite. App. Catal. A: Gen. 1999, 177, 1-8. 
28. Lee, B.I.; Bae, D.; Kang, J.-K.; Kim, H.; Byeon, S.-H. Synthesis of SBA-15 Supported Rh Nanoparticles with High Loading Density and its Catalytic Hydrogenation of Phenol in Supercritical Carbon Dioxide. Bull. Korean Chem. Soc. 2009, 30, 1701-1702.

29. Sharma, R.V.; Baroi, C.; Dalai, A.K. Production of biodiesel from unrefined canola oil using mesoporous sulfated Ti-SBA-15 catalyst. Catal. Today 2014, 237, 3-12.

30. Jin, M.; Kim, J.H.; Kim, J.M.; Jeon, J.-K.; Jurng, J.; Bae, G.-N.; Park, Y.-K. Benzene oxidation with ozone over MnOx/SBA-15 catalysts. Catal. Today 2013, 204, 108-113.

31. Cao, Y.-L.; Wang, J.-W.; Li, Q.-F.; Yin, N.; Liu, Z.-M.; Kang, M.-Q.; Zhu, Y.L. Hydrolytic hydrogenation of cellulose over $\mathrm{Ni}_{-} \mathrm{WO}_{3} / \mathrm{SBA}-15$. J. Fuel Chem. Technol. 2013, 41, 943-949.

32. Zhu, Q.; Maeno, S.; Nishimoto, R.; Miyamoto, T.; Fukushima, M. Oxidative degradation of pentabromophenol in the presence of humic substances catalyzed by a SBA-15 supported iron-porphyrin catalyst. J. Mol. Catal. A. Chem. 2014, 385, 31-37.

33. Ojeda, M.L.; Esparza, J.M.; Campero, A.; Cordero, S.; Kornhauser, I.; Rojas, F. On comparing BJH and NLDFT pore-size distributions determined from $\mathrm{N}_{2}$ sorption on SBA-15 substrata. Phys. Chem. Chem. Phys. 2003, 5, 1859-1866.

34. Villarroel-Rocha, J.; Barrera, D.; Sapag, K. Introducing a self-consistent test and the corresponding modification in the Barrett, Joyner and Halenda method for pore-size determination. Microporous Mesoporous Mater. 2014, 200, 68-78.

35. Barrett, E.P.; Joyner, L.G.; Halenda, P.P. The determination of pore volume and area distributions in porous substances. I. Computations from nitrogen isotherms. J. Am. Chem. Soc. 1951, 73, 373-380.

36. Zhao, D.; Huo, Q.; Feng, J.; Chmelka, B.F.; Stucky, G.D. Nonionic triblock and star diblock copolymer and surfactant syntheses of highly ordered, hydrothermally stable, mesoporous silica structures. J. Am. Chem. Soc. 1998, 120, 6024-6036.

37. Sing, K.S.W.; Everett, D.H.; Haul, R.A.W.; Moscou, L.; Pierotti, R.A.; Rouquerol, J.; Siemieniewska, T. Reporting physisorption data for gas/solid systems with special reference to the determination of surface area and porosity. Pure Appl. Chem. 1985, 57, 603-619.

38. Broekhoff, J.C.P. Mesopore determination from nitrogen sorption isotherms: Fundamentals, scope, limitations. Stud. Surf. Sci. Catal. 1979, 3, 663-684.

39. Moreno-Piraján, J.C.; Giraldo, L. Lipase supported on mesoporous materials as a catalyst in the synthesis of biodiesel from Persea americana mill oil. J. Mol. Catal. B: Enzym. 2012, 156, 45-50.

40. Yang, Y.; Karmakar, S.; Zhang, J.; Yu, M.; Mitter, N.; Yu, C. Synthesis of SBA-15 rods with small sizes for enhanced cellular uptake. J. Mater. Chem. B 2014, 2, 4929-4934.

41. Titirici, M.M.; Thomas, A.; Antonietti, M. Aminated hydrophilic ordered mesoporous carbons. J. Mater. Chem. 2007, 17, 3412-3418.

42. Margolese, D.; Melero, J.A.; Christiansen, S.C.; Chmelka, B.F.; Stucky, G.D. Direct syntheses of ordered SBA-15 mesoporous silica containing sulfonic acid groups. Chem. Mater. 2000, 12, 2448-2459.

43. Chen, G.; Guo, C.-Y.; Zhang, X.; Huang, Z.; Yuan, G. Direct conversion of syngas to ethanol over Rh/Mn-supported on modified SBA-15 molecular sieves: Effect of supports. Fuel Process. Technol. 2011, 92, 456-461. 
44. Wang, H.-B.; Zhang, Y.-H.; Yang, H.-L.; Ma, Z.-Y.; Zhang, F.-W.; Sun, J.; Ma, J.-T. Palladium immobilized in the nanocages of SBA-16: An efficient and recyclable catalyst for Suzuki coupling reaction. Microporous Mesoporous Mater. 2013, 168, 65-72.

45. Rivera-Muñoz, E.M.; Huirache-Acuña, R. Sol gel-derived SBA-16 mesoporous material. Int. J. Mol. Sci. 2010, 11, 3069-3086.

46. Sun, H.; Tang, Q.; Du, Y.; Liu, X.; Chen, Y.; Yang, Y. Mesostructured SBA-16 with excellent hydrothermal, thermal and mechanical stabilities: Modified synthesis and its catalytic application. J. Colloid Interface Sci. 2009, 333, 317-323.

47. Jeon, G.S.; Chung, J.S. Preparation and characterization of silica-supported copper catalysts for the dehydrogenation of cyclohexanol to cyclohexanone. Appl. Catal. A 1994, 115, 29-44.

48. Scirè, S.; Minicò, S.; Crisafulli, C. Selective hydrogenation of phenol to cyclohexanone over supported Pd and Pd-Ca catalysts: An investigation on the influence of different supports and Pd precursors. Appl. Catal. A 2002, 235, 21-31.

49. Velu, S.; Kapoor, M.P.; Inagaki, S.; Suzuki, K. Vapor phase hydrogenation of phenol over palladium supported on mesoporous $\mathrm{CeO}_{2}$ and $\mathrm{ZrO}_{2}$. Appl. Catal. A 2003, 245, 317-331.

Sample Availability: Samples are not available.

(C) 2014 by the authors; licensee MDPI, Basel, Switzerland. This article is an open access article distributed under the terms and conditions of the Creative Commons Attribution license (http://creativecommons.org/licenses/by/4.0/). 